\title{
Influencing factors and health risk assessment of microcystins in the Yongjiang river (China) by Monte Carlo simulation
}

\author{
Chan-Chan Xiao ${ }^{1}$, Mao-Jian Chen ${ }^{2}$, Fan-Biao Mei ${ }^{1}$, Xiang Fang ${ }^{1}$, Tian-Ren Huang ${ }^{1}$, Ji-Lin Li ${ }^{1}$, Wei Deng \\ Corresp., 1 , Yuan-Dong Li ${ }^{\text {Corresp. } 1}$ \\ 1 Department of Experimental Research, Affliated Tumor Hospital of Guangxi Medical University, Nanning, China \\ 2 Department of Breast Surgery, Affiliated Tumor Hospital of Guangxi Medical University, Nanning, China \\ Corresponding Authors: Wei Deng, Yuan-Dong Li \\ Email address: dengwei@gxmu.edu.cn, lyd641209@163.com
}

The Yongjiang river is a large, shallow, hyper-trophic, freshwater river in Guangxi, China. To investigate the presence of microcystin-RR, microcystin-LR, and microcystin-YR ( MC$R R, M C-L R$ and MC-YR) in the Yongjiang river and describe their correlation with environmental factors, as well as, assess health risk using Monte Carlo simulation, 90 water samples were collected at three sample points from March-December 2017. Results showed that during the monitoring period, total concentrations of MC-RR (TMC-RR), MC-YR (TMC-YR), and MC-LR (TMC-LR) varied from 0.0224 to $0.3783 \mu \mathrm{g} / \mathrm{L}, 0.0329$ to $0.1433 \mu \mathrm{g} / \mathrm{L}$, and 0.0341 to $0.2663 \mu \mathrm{g} / \mathrm{L}$, respectively. Total phosphorus (TP) content appeared to be related to TMC-LR and the total content of microcystins (TMCs), while $\mathrm{pH}$ and total nitrogen/total phosphorus (TN/TP) ratio appeared to be related to TMC-RR and TMC-YR, respectively. Using the professional health risk assessment software @Risk7.5, the risks of dietary intake of microcystins (MCs), including the carcinogenic risk and non-carcinogenic risk, were evaluated. It was found that the carcinogenic risk of MC-RR from drinking water was higher than MC-LR and MC-YR, and the presence of MCs would lead to high potential health risks, especially in children. The carcinogenic risk of MC-RR to children was > $1 \times 10^{-4}$, the maximum allowance level recommended by the US Environmental Protection Agency (USEPA); as for adults, it was $>5 \times 10^{-5}$, the maximum allowance level recommended by the International Commission on Radiological Protection (ICRP). The noncarcinogenic hazard index of MC-RR, MC-YR, and MC-LR increased successively, indicating that MC-LR was more hazardous to human health than MC-YR and MC- RR, but its hazard index was $<1$. This suggests that MCs pose less risk to health. However, it is necessary to strengthen the protection and monitoring of drinking water source for effective control of water pollution and safeguarding of human health. 


\section{Influencing factors and health risk assessment of microcystins in the 2 Yongjiang river (China) by Monte Carlo simulation}

3 Chan-Chan Xiao ${ }^{1}$, Mao-Jian Chen ${ }^{2}$, Fan-Biao Mei ${ }^{1}$, Xiang Fang ${ }^{1}$, Tian-Ren Huang ${ }^{1}, \mathrm{Ji}^{-}$-lin $\mathrm{Li}^{1}$,

4 Wei Deng ${ }^{1, *}$, Yuan-Dong $\mathrm{Li}^{1, *}$

$5 \quad{ }^{1}$ Department of Experimental Research, Affiliated Tumor Hospital of Guangxi Medical

6 University, Nanning, Guangxi Zhuang Autonomous Region, China

$7 \quad{ }^{2}$ Department of Breast Surgery, Affiliated Tumor Hospital of Guangxi Medical University,

8 Nanning, Guangxi Zhuang Autonomous Region, China

9 Corresponding Author: Wei Deng ${ }^{*}, Y u a n-D o n g ~ \mathrm{Li}^{*}$

10 *Department of Experimental Research, Affiliated Tumor Hospital of Guangxi Medical

11 University, Nanning, Guangxi Zhuang Autonomous Region, China

12 Email address: Wei Deng, dengwei@gxmu.edu.cn 


\section{ABSTRACT}

22 The Yongjiang river is a large, shallow, hyper-trophic, freshwater river in Guangxi, China. To

23 investigate the presence of microcystin-RR, microcystin-LR, and microcystin-YR ( MC-RR, MC-LR and MC-YR) in the Yongjiang river and describe their correlation with environmental factors, as well as, assess health risk using Monte Carlo simulation, 90 water samples were collected at three sample points from March-December 2017. Results showed that during the monitoring period, total concentrations of MC-RR (TMC-RR), MC-YR (TMC-YR), and MC-LR (TMC-LR) varied from 0.0224 to $0.3783 \mu \mathrm{g} / \mathrm{L}, 0.0329$ to $0.1433 \mu \mathrm{g} / \mathrm{L}$, and 0.0341 to 0.2663 $\mu \mathrm{g} / \mathrm{L}$, respectively. Total phosphorus (TP) content appeared to be related to TMC-LR and the total content of microcystins (TMCs), while $\mathrm{pH}$ and total nitrogen/total phosphorus (TN/TP) ratio appeared to be related to TMC-RR and TMC-YR, respectively. Using the professional health risk assessment software @Risk7.5, the risks of dietary intake of microcystins (MCs), including the carcinogenic risk and non-carcinogenic risk, were evaluated. It was found that the carcinogenic risk of MC-RR from drinking water was higher than MC-LR and MC-YR, and the presence of MCs would lead to high potential health risks, especially in children. The

allowance level recommended by the US Environmental Protection Agency (USEPA); as for adults, it was $>5 \times 10^{-5}$, the maximum allowance level recommended by the International 
39 Commission on Radiological Protection (ICRP). The non-carcinogenic hazard index of MC-RR,

40 MC-YR, and MC-LR increased successively, indicating that MC-LR was more hazardous to

41 human health than MC-YR and MC- RR, but its hazard index was $<1$. This suggests that MCs

42 pose less risk to health. However, it is necessary to strengthen the protection and monitoring of

43 drinking water source for effective control of water pollution and safeguarding of human health.

44

\section{INTRODUCTION}

Eutrophication of freshwater bodies can result in algal blooms, especially those caused by cyanobacteria. The algal toxins secreted from cyanobacteria are possibly harmful to plants, animals, and humans (Holland \& Kinnear, 2013; Cao et al., 2017). So far, most of as-known 90 microcystins(MCs) have been isolated from species and strains of Microcystis (Pham \&Utsumi, 2018). Among them, the most widely distributed are microcystin-LR (MC-LR), microcystinRR(MC-RR), and microcystin-YR (MC-YR) (Zegura, 2016). These toxins are synthesized in the cells and released after cell rupture, finally appeared as MCs in the water source.

Cyanobacteria blooms exist in eutrophicated waters worldwide, so that MCs can be bioaccumulated by aquatic animals and reach human bodies. These would severely harm human health and cause illness or deaths. In 1975, the drinking water source in the small town of Pennsylvania was contaminated by Microcystis, which resulted in acute gastroenteritis for over half of the local population (Keleti et al., 1979; Keleti \& Sykora, 1982; Lippy \& Erb, 1976). In 1996, due to contamination by MCs occurring in a hemodialysis center in Brazil, 116 of 130 patients developed symptoms of blurred vision and nausea, and $>50$ individuals succumbed to to 
59 mortality (Pouria et al., 1998). Studies on drinking water showed that with drinking ditch pond

60 water containing MCs, the mortality rate of local people in Haimen and Fu Sui caused by

61 hepatocellular carcinoma (HCC) reached about 100/100,000, which was significantly higher than

62 that of shallow wells or deep wells $(20 / 100,000)$ (Ueno et al., 1996). In 2010, the International

63 Agency for Research on Cancer (IARC) listed MCs as a "possible human carcinogen" (Group

64 2B) based on its potential carcinogenicity (IARC, 2010).

Although it has been confirmed that MCs can cause acute and chronic damage to human

66 bodies, the risk assessment of MC-LR, MC-RR, and MC-YR in the Yongjiang river of China

67 remains lack of reports. The environmental conditions of water source are crucial in the concentration levels of toxins. However, the factors affecting the concentration levels of MCs

69 (nutrient levels and climatic conditions) in Yongjiang have not yet been elucidated. Therefore, it is urgent to investigate the concentration and distribution of MCs in Yongjiang river as

71 influenced by seasonal changes in water quality and the related parameters.

72 Owing to the limitations of conducting toxicological health risk assessments in a population, 73 the Monte Carlo simulation (mathematical and logical model) has been widely used in recent 74 years. It was used to understand the behavior of water systems by assuming different problems 75 and systems, showing an advantage over experiments(Clausen et al., 2017). Moreover, the 76 Monte Carlo simulation of uncertainties was applied in the risk assessment model by collecting 77 limited samples to predict the overall situation. As a result, the risk uncertainty was expressed 78 intuitively, in agreement with the order of the nature, which favors for a decision-making for risk 
managers and policymakers(Paladino, Moranda \& Seyedsalehi, 2017; Sasi, Yozukmaz \& Yabanli, 2017). The US Environmental Protection Agency (USEPA) has set Monte Carlo simulation as a basic method in the risk analysis policy(Moolenaar, 1996). Currently, American Palisade has developed the @Risk Monte Carlo software loading into Excel simulation technology for risk assessments. It is mainly based on the analysis of stochastic simulation method of Monte Carlo, which provides various predicted results by using a variety of probabilistic simulations, including the occurrence probability of events with a risk, forecasting the risk of uncertainty quantitatively, and summarizing the characterization results. For instance, Li et al. (2017) used the Monte Carlo model to assess the quantitative risk of aluminum in Youtiao, which did not exceed the provisional tolerable weekly intake (PTWI) set by the Joint Expert Committee on Food Additives (JECFA) for the public. Jia et al. (2018) used the Monte Carlo simulation to evaluate the trace elements in the four freshwater fishes from a mineimpacted river, and found that the consumption did not exert any appreciable adverse impact on human health due to the exposure to trace elements in fish muscle.

This study investigated the current status of drinking water sources in the Yongjiang river in China with respect to the contamination of MCs. The professional health risk assessment software@Risk7.5 was used to evaluate the risks of dietary intake of MCs, including the carcinogenic and non-carcinogenic risks. These findings provide a basis to develop an effective control of water pollution and quality in order to protect the human health in the specific area.

\section{MATERIALS AND METHODS}


99

100

101

102

103

104

105

106

107

108

109

110

111

112

113

114

115

116

117

118

\subsection{Sampling location}

The Yongjiang river is a major water resource with an average annual flow of $1292 \mathrm{~m}^{3} / \mathrm{s}$ in the

Nanning City area (Figure 1). The surface area of the river is 2676 ha with a maximum depth of $23 \mathrm{~m}$. It is the main urban water source in Nanning city, China, and the tributary channel is also a vital transportation route. Except for that, it is used for recreation as well as the source of water for domestic use, agriculture, fishery, and industry.

\subsection{Sampling}

Water samples were collected from the Yongjiang river in Nanning City from March to December in 2017. For this, the river section was set into three sampling points: Qingxiu District, Jiangnan District, and Yongning District (Figure 1). The water samples were collected at a depth of $0.5 \mathrm{~m}$ and 3 times/month from each sampling point. Thus, a total of 90 samples were collected during the most active daylight period (11:00-14:00) in 10 months. Sample collecting, containers, stabilization, and transportation to the laboratory were in accordance with the methods described in Wunderlin et al. (2001). Water samples were filtered through the 500 mesh stainless steel screensto remove large particles and were stored at $4{ }^{\circ} \mathrm{C}$ with the protection from light, finally processed within 24 hours. A volume of $2000 \mathrm{~mL}$ water sample was collected, and $500 \mathrm{~mL}$ water sample is passed through the $0.45 \mu \mathrm{m}$ filter (Jinteng, China) under reduced pressure filtration. The filter containing the algae was subjected to an extraction process in order to recover the intracellular MCs, followed by two extractions with $5 \mathrm{~mL}$ ultra-pure water after five times freezing-thawing at $-80^{\circ} \mathrm{C} / 37^{\circ} \mathrm{C}$. After filtering through the $0.45 \mu \mathrm{m}$ filter for removing the algal 
119

120

121

122

123

124

125

126

127

128

129

130

131

132

133

134

135

136

137

138

cells, the filtrates and the extracts from the filter were passed through solid phase extraction (SPE) (500 mg/6 mL) (SUPELCO, USA). The SPE was rinsed with $20 \mathrm{~mL}$ of $20 \%$ methanol and 10 $\mathrm{mL}$ deionized distilled water. The toxin was eluted from the stationary phase with $80 \%$ methanol (containing $0.05 \%$ TFA), and each sample was dried in a water bath under control temperature $\left(60^{\circ} \mathrm{C}\right)$.

\subsection{Water quality analysis}

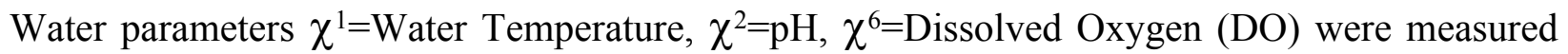
in situ and $\chi^{3}=$ Total phosphorus (TP), $\chi^{4}=\mathrm{PO}_{4}{ }^{3-}-\mathrm{P}$ and $\chi^{5}=$ Total Nitrogen $(\mathrm{TN})$ were measured in the laboratory. Each experiment was performed in triplicate, and the average values were reported. All water samples were analyzed using standard methods (GB, 2002). The instruments used were YSI Model 58 thermometer, Knick Portamess 911 for $\mathrm{pH}$ measurement. DO using iodometric method. TN and TP were analyzed using Kjeldahl method and persulfate digestion. $\mathrm{PO}_{4}{ }^{3-}-\mathrm{P}$ was determined according to stannous chloride method.

\subsection{Determination of MCs}

The air-dried samples were suspended into $1 \mathrm{~mL}$ deionized distilled water for high performance liquid chromatography (HPLC) (Shimadzu LC-20A, Japan) analysis. The solubilized toxin samples were analyzed using HPLC with UV detector at $238 \mathrm{~nm}$ and symmetrical C18 column $(3.9 \times 150 \mathrm{~mm})$ (Waters, USA). The mobile phase consists of $33 \%$ acetonitrile and $67 \%$ deionized distilled water in $0.1 \%$ phosphate buffer $(\mathrm{pH}=3.0)$. The flow rate was set at $1 \mathrm{~mL} / \mathrm{min}$. The injection volume was $20 \mu \mathrm{L}$ and the column temperature was $45^{\circ} \mathrm{C}$. $\mathrm{MC}-\mathrm{LR}$ and $\mathrm{MC}-\mathrm{RR}$ 
139 (Solarbio, approximate purity, 95\%) and MC-YR (Alexis, approximate purity 98\%) were used as

140 standards. Furthermore, the concentrations of MCs were determined by calibrating such area

141 under the peak with the corresponding standard curves. MC-LR, MC-RR, and MC-YR showed a

142 good linearity in the range of $0.025-2 \mu \mathrm{g} / \mathrm{L}\left(\mathrm{r}^{2}=0.9987,0.9992,0.9997\right)$. Under the condition that

143 the signal to noise ratio $(\mathrm{S} / \mathrm{N})$ is 3 , the detection limits of MC-RR and MC-LR is $0.0125 \mu \mathrm{g} / \mathrm{L}$,

144 and the detection limit of MC-YR is $0.014 \mu \mathrm{g} / \mathrm{L}$. The recoveries ranged from $91 \%$ to $110 \%$, the

145 relative standard deviation (RSD) was $3.0 \%$ to $5.6 \%$. A series of toxin peaks were identified

146 using retention time and compared with spikes and known standards in the blank samples.

147 Furthermore, the concentrations of MCs were determined by calibrating such area under the peak

148 with corresponding standard curves. The order of the peaks and time of each standard substance

149 were as follows: MC-RR (7.599 min), MC-YR (14.225 min), and MC-LR (17.601 min). The test

150 sample was analyzed in $18 \mathrm{~min}$ (Figure 2).

\subsection{Method of risk assessment}

\subsubsection{Construction of exposure assessment model}

153 The three main routes of exposure to pollutants were consumption, inhalation, and skin

154 absorption. The proportion of each varied in different pollutants. This study assessed the

155 exposure risk caused by the drinking water. The daily exposure to MC-RR, MC-YR, and MC-LR

156 in the drinking water was assessed using Monte Carlo simulation by@Risk7.5 software

157 operating platform, while the Bootstrap sampling method was used for quantifying the

158 uncertainty. Each Bootstrap sample was simulated with 10,000 Monte Carlo simulations to 
159

160

161

162

163

164

165

166

167

168

169

170

171

172

173

174

175

176

determine its uncertainty by obtaining different percentile values (P5-P95). The probabilistic assessment method was used to construct the exposure evaluation model (Zobitz et al., 2011).

The mechanism underlying the different exposures and various routes with different exposure dose formula were employed for the exposure assessment model of the health risk of chemical pollutants from the USEPA. Chronic daily intake (CDI) evaluated the safety of MCs in drinking water and the health risks of diverse routes in different populations. The CDI ( $\mu \mathrm{g} / \mathrm{kg} / \mathrm{day})$ formula for daily exposure of drinking water (Duy et al., 2000; Funari \& Testai, 2008) is as follows:

$$
\mathrm{CDI}=\frac{\mathrm{CW} \times \mathrm{IR} \times \mathrm{EF} \times \mathrm{ED}}{\mathrm{BW} \times \mathrm{AT}}
$$

Here, $\mathrm{Cw}$ is the concentration of pollutants in the water, $\mu \mathrm{g} / \mathrm{L}$; IR is the volume of drinking water (L/day); EF is the frequency of exposure, drinking water for daily necessities (365 days/year); $\mathrm{ED}$ is exposure duration (years); $\mathrm{BW}$ is the average body weight, $\mathrm{kg}$; $\mathrm{AT}$ is the average time equal to ED multiplied by 365 days/year. According to the World Health Organization (WHO), the standard weight of adults is $70 \mathrm{~kg}$, and the daily drinking volume is $2 \mathrm{~L} /$ day; while the weight of children is $16 \mathrm{~kg}$ and the daily drinking volume is $1 \mathrm{~L} /$ day $(\mathrm{WHO}, 2017)$.

\subsubsection{Construction of risk description model}

The characteristics of the pollutants in a water environment are generally divided into genetic, toxic substances (for instance, chemical carcinogens), and somatic toxic substances (for instance, non-carcinogens) as recommended by the USEPA water environmental health risk assessment 
177 model. The carcinogenic and non-carcinogenic risks of MCs in source waters are evaluated from 178 exposure pathways.

179

(1) Health hazard risk model of chemical carcinogens

The formula of health hazard risk caused by chemical carcinogens recommended by USEPA

181 (Duy et al., 2000):

$$
R_{i}{ }^{c}=\frac{1-\exp \left(-D_{i} q_{i}\right)}{70}
$$

182

In the formula, $\mathrm{R}_{\mathrm{i}}{ }^{\mathrm{c}}$ is the average personal carcinogenic annual risk of chemical carcinogen $\mathrm{i}$

184

185

Dietrich, 2000), this study deduced the formula as follows:

$$
\mathrm{CPI}=\underline{(\mathrm{OR}-1) \times \mathrm{LR}}
$$

D

190 Where carcinogenic potency index (CPI) is the coefficient of carcinogenic strength estimated 191 from the population data: $\mathrm{q}_{\mathrm{i}}, \mathrm{kg} / \mathrm{day} / \mu \mathrm{g} / \mathrm{L}$. Odds ratio $(\mathrm{OR})$ refers to the ratio of the number of 192 exposed and non-exposed people in the case group divided in the control group. According to the 
193

194

195

196

197

198

199

200

201

202

203

204

205

206

207

208

209

210

211

population of 80,000 inhabitants, the study showed that the person who drank the river water presented a liver cancer OR of 1.246 (Falconer \& Buckley, 1989; Yeh et al., 1989; Yu, Chen \& Li, 1995). Lifetime risk (LR) indicated the risk of cancer among individuals in the whole local population; according to the risk of cancer during the individual's lifespan exposed to MC-LR in the population of China, which was $6.2 \times 10^{-3}$ (Yeh et al., 1989; Fan et al.,2009). D indicated the calculation of the average daily life exposure dose, $\mu \mathrm{g} / \mathrm{kg} / \mathrm{day}$. According to the study by Wolf et al., the lifetime carcinogenic strength of MC-RR is $1 / 10^{\text {th }}$ of that of MC-LR, while the strength of carcinogenicity of MC-YR and MC-LR was equivalent (Wolf \& Frank, 2002).

(2) Non-carcinogenic health risk assessment model

The health risk assessment model recommended by USEPA was used to evaluate the noncarcinogenic health risk of MCs in the Yongjiang river source water. The non-carcinogenic risk was described using a hazard index (HI) by the following formula:

$$
\mathrm{HI}=\frac{\mathrm{CDI}}{R f D}
$$

Here, reference dose $(R f D)$ is the reference dose for MCs: the internationally accepted tolerable daily intake (TDI) instead of MC-LR RfD was $0.04 \mu \mathrm{g} / \mathrm{kg} / \mathrm{d}$. According to the equivalent toxicity relationship among MC-RR, MC-YR, and MC-LR, the RfD values of MC-RR and MC-YR were 0.4 and $0.04 \mu \mathrm{g} / \mathrm{kg} / \mathrm{d}$, respectively (Wolf \& Frank, 2002; Lee et al., 2017).

The $\mathrm{HI}$ is usually used as a benchmark of danger: $\mathrm{HI}>1$ indicates that the exposure higher than 
212 the reference dose is harmful to the human body; $\mathrm{HI} \leq 1$ indicates that the exposure level is lower

213 than the reference dose, which is unlikely to be detrimental (Younes, 1999).

\section{$214 \quad$ 2.6. Statistical analysis}

215 The IBM SPSS Statistics 22.0 software was used to perform all descriptive statistical analysis, 216 including minimum value, maximum value, mean value, standard deviation, Pearson's 217 correlation analysis, and stepwise multiple linear regression. Moreover, the risk assessment of 218 MC-RR, MC-YR, and MC-LR exposure in water source was carried out using@Risk7.5 219 probabilistic evaluation software based on the Monte Carlo simulation technique.

\section{3. RESULTS}

3.1. Concentration level, distribution characteristics, and environmental impact factors of

MCs in source water

\subsubsection{Concentration distribution characteristics of MCs in source water}

The concentrations of MC-LR, MC-RR, and MC-YR in water samples were detected. The total concentrations of MCs (TMCs) in water are the sum of the concentrations of extracellular MCs (EMCs) and intracellular MCs (IMCs) dissolved in the water. The results were summarized in 227 Table 1.

\subsubsection{Seasonal distribution characteristics of MCs in water samples}


230 of TMC-YR (referring to the sum of intracellular and extracellular, the same to the other twos)

231 was significantly lower than the other two MCs. The concentrations of TMC-RR and TMC-YR

232 at the same time reached the maximum levels in October.

\subsubsection{Pearson's correlation analysis of environmental factors and MCs' concentration}

234 Pearson's correlation analysis of environmental factors and MCs' concentration were analyzed 235 and the results were shown in Table 2. According to the correlation analysis, the concentration of 236 TMC-RR was positively correlated with water temperature and $\mathrm{TN}(p<0.01)$ with a significant 237 negative correlation with $\mathrm{pH}(p<0.01)$. The concentration of TMC-YR was negatively correlated 238 with TN:TP ratio $(p<0.05)$. The concentration of TMC-LR was positively correlated with water 239 temperature, TP, and $\mathrm{PO}_{4}{ }^{3-}-\mathrm{P}(p<0.01)$ with a significant negative correlation with $\mathrm{DO}$ and 240 TN:TP ratio $(p<0.01)$. The concentration of TMCs was positively correlated with water 241 temperature and TP $(p<0.01)$ with a significant negative correlation with $\mathrm{pH}$, DO, and TN:TP 242 ratio $(p<0.01)$.

243 3.1.4. Stepwise multiple linear regression analysis of MCs' concentration and 244 environmental factors

245 A stepwise multiple linear regression analysis of MCs' concentration and environmental factors

246 is shown in Table 3. The results indicated that TP $\left(\chi^{3}\right)$ is the dominant factor affecting the 247 contents of TMC-LR and TMCs. $\mathrm{pH}\left(\chi^{2}\right)$ and TN:TP ratio $\left(\chi^{7}\right)$ are the primary factors affecting 248 the content of TMC-RR and TMC-YR, respectively. These findings were in agreement with the 249 results of correlation analysis. 


\subsubsection{Distribution fitting of the concentration of MCs in source water}

252 The@Risk7.5 software to is used to fit the processed samples. The concentration of MCs in 253 source water were characterized as continuous data. The fitting results were followed by the 254 optimal fitting distribution models: Gamma, Invgauss, Lognorm, Expon, and Loglogistic. Three 255 main methods were used to test the goodness of the fittings: Chi-Sq (Chi-squared) test, K-S 256 (Kolmogorov-Smirnov) test, and A-D (Anderson-Darling) test (Lipton et al., 1995; Cummins et 257 al., 2009). Above all, the sample fitting results (Table 4) were used to determine the fitting 258 distribution types of the optimal probability of the pollution data: MC-RR had Gamma and 259 Invgauss distribution, MC-YR had Lognorm, Expon, and Loglogistic distribution, and MC-LR 260 had Gamma and Expon distribution. Furthermore, the results of the distribution parameters after 261 fitting and the comparison with the sample data parameters are summarized in Table 5. The 262 probability distribution of the mass concentration of MCs, MC-RR, MC-YR, and MC-LR in 263 source water is shown in Figures 4, 5, and 6. The fitting results can be visually observed from the 264 coincidence of the blue rectangular shape and the area under the red curve.

\subsubsection{Daily exposure calculation}

The @Risk7.5 software was utilized for the random extraction of the MCs concentration profiles

267 from the water to calculate the daily exposure of direct drinking water by different populations to MC-RR, MC-YR, and MC-LR. Each simulation cycle was performed for 10,000 cycles, and the simulation results are shown in Table 6. A significant difference between adults and children was 
270

271

272

273

274

275

276

277

278

279

280

281

282

283

284

285

286

287

288

289

observed in the daily exposure. P50, P85, P90, and P95 (Table 6) represent the high exposure sites of each population. The MCs exposed to drinking water showed that the children's daily intake was 2-fold higher than that of the adults, suggesting that children are more susceptible to the pollution of MCs than adults.

\subsection{Risk characterization of MCs in source water}

\subsubsection{Carcinogenic risk of MCs in source water}

Based on the exposure parameters and carcinogenic risk formula,@Risk7.5 risk analysis software was used to extract the numerical the value of MCs concentration in water randomly and calculate the carcinogenic risk of MC-RR, MC-YR, and MC-LR intake by different groups of individuals through direct drinking water. Each simulation cycle of 10,000 displayed the statistical simulation results summarized in Table 7. The carcinogenic annual risk of MC-YR was less than that of MC-LR and MC-RR, and MC-RR was the primary hazard in the source water. The maximum acceptable level and the negligible level of the carcinogenic risk for the population recommended by some institutions are listed in Table 8; the annual risk in carcinogenesis of MCs in a water source is $10^{-6}$ to $10^{-4}$.(NHMRC \& NRMMC, 2011). The carcinogenic risk of MC-YR and MC-LR in adults and children was lower than the maximum acceptable risk level designated by USEPA $\left(1 \times 10^{-4}\right)$ and ICRP $\left(5 \times 10^{-5}\right)$, and the risk of carcinogenesis in children was higher than that in adults. The health risks caused by MC-RR from drinking water source for children was significantly higher than the maximum allowance level recommended by USEPA $\left(1 \times 10^{-4}\right)$. Similarly, the health risks caused by the MC-RR from 
290 drinking water source for adults were significantly higher than the maximum allowance level

291 recommended by ICRP $\left(5 \times 10^{-5}\right)$. These statistical details indicated that MC-RR in water bodies

292 exhibited a significant carcinogenic risk to the health of adults and children.

\subsubsection{Non-carcinogenic risk of MCs in source water}

294 The exposure parameters and non-carcinogenic hazards index formula were used to calculate the 295 values of different populations through direct drinking water intakes of MC-RR, MC-YR, and 296 MC-LR (Table 9). These findings demonstrated that the average non-carcinogenic hazards index 297 of MCs in different populations through drinking water intake and the non-carcinogenic hazards 298 index of P90 and P95 at high level of exposure was $<1$. This suggested that MCs, which are 299 ingested through drinking water, pose less risk to health. The non-carcinogenic hazard index of 300 MC-RR, MC-YR, and MC-LR increased successively, indicating that MC-LR was more 301 hazardous to human health than MC-YR and MC-RR. Although the MC-RR, MC-YR, and MC302 LR display a non-carcinogenic index in children than adults, and thus, MCs are detrimental to 303 children.

\section{4. DISCUSSION} The World Health Organization established a guide value of $1 \mu \mathrm{g} / \mathrm{L}$ for MC-LR concentration in drinking water (WHO, 2017). A comprehensive Australian report shows that the concentration of total MCs in drinking water should not exceed $1.3 \mu \mathrm{g} / \mathrm{L}$, expressed as MC-LR toxicity 
309

310

311

312

313

314

315

316

317

318

319

320

321

322

323

324

325

326

327

$\mathrm{mm}^{3} / \mathrm{L}$ ) would be equivalent to the guideline of $1.3 \mu \mathrm{g} / \mathrm{L}$ MC-LR toxicity if the toxin was fully released into the water(NHMRC \& NRMMC, 2011). In the study of a Canadian group, the recommended maximum acceptable level (MAL) in drinking water is $0.5 \mu \mathrm{g} / \mathrm{L}$ of MC-LR, or in the absence of potency equivalency values for other MCs, $1 \mu \mathrm{g} / \mathrm{L}$ of total MCs (Watanabe et al., 1996).

By monitoring of the water quality in the Yongjiang river, we demonstrated that although no major algal bloom occurred, MC-RR, MC-YR, and MC-LR were present in the water column during the monitoring period. The TMCs concentrations varied from 0.0313 to $0.4585 \mu \mathrm{g} / \mathrm{L}$. An earlier study of MCs in Guangxi showed that the average concentration of MCs in source water and treated water supplies were $0.277 \mu \mathrm{g} / \mathrm{L}$ and $0.221 \mu \mathrm{g} / \mathrm{L}$, respectively(Lv et al., 2005). Another survey showed that the concentration of MCs in the source water of high-incidence areas of liver cancer in Guangxi was $15.64 \pm 2.08 \mathrm{ng} / \mathrm{L}$, and the concentration in treated water supplies was $14.42 \pm 2.28 \mathrm{ng} / \mathrm{L}$ (Li et al., 2016). These results suggest that MCs are detected in parts of Guangxi, but without considering the influencing factors and health risk assessment of MCs. The collected data indicated that the peak level in October followed by a sharp drop in concentration when using TMCs content as an indicator (Figure 3). The significant decrease in TMCs content may result from the decreasing of temperature from November to December, and result in a slow growth of Microcystis. These phenomena were similar to those described by previous groups in Tai, Yang-cheng, and Xuanwu lakes in China(Xu et al., 2010; Li, Gu \& He, 
329

330

331

332

333

334

335

336

337

338

339

340

341

342

343

344

345

346

347

348

average concentration level in November. As compared to the concentration of the above two toxins, TMC-YR concentration was the lowest of the three toxins studied; these results were identical to findings by other researchers, which suggested that the MCs are primarily dominated by TMC-RR and TMC-LR (Yang et al., 2006; Bi et al., 2017). It was clearly shown that the concentration of TMC-LR gradually increased from September to November. Such variation may be influenced by the differences in nutrients and climates, which are in favor of TMC-RR, TMC-LR and to a lesser extent TMC-YR.

Previous studies demonstrated that the algal toxins are produced by algae and consequently the concentration of toxins in water depends mainly on algal abundance (or biomass) such as chlorophyll-a concentration or algal cell counts, which in turn, is regulated by the environmental factors. The relationship of physical and chemical water parameters to the concentration levels of toxins are shown in Table 2. In this study, it was evident that temperature was positive and significantly correlated with concentration levels of TMCs, TMC-LR, TMC-RR and weakly associated with concentration levels of TMC-YR. The highest concentrations of TMCs and TMC-RR, TMC-LR were observed in October and November with surface water temperature were around $25.6^{\circ} \mathrm{C}$ and $26.2^{\circ} \mathrm{C}$, respectively. When water temperature increased, even higher concentration of TMCs and TMC-RR, TMC-LR concentration were detected. These findings are in agreement with previous reports which showed the concentrations of TMCs and TMC-RR, TMC-LR were temperature dependent, and TMC-RR which are generally detected at lower temperatures as compared to TMC-LR which favors at higher temperatures(Wang et al., 2010; 
349 Mantzouki et al., 2018). Intriguingly, the $\mathrm{pH}$ value was also shown to be related to the 350 concentration level of toxins in the Yongjiang river. The maximum toxin concentration was 351 detected at a $\mathrm{pH}$ below or above the medium level. As a result, TMC-RR and TMCs were 352 negatively correlated with $\mathrm{pH}$ value (Table 2), which was similar to the results of other studies.

353 Notably, the phytoplankton is known to affect the $\mathrm{pH}$, and then, further affects the concentration

354 leves of toxins. Therefore, the $\mathrm{pH}$ value cannot be used as an appropriate parameter to determine 355 the concentration levels of toxins. A majority of the blue-green algae can grow adequately in the water at $\mathrm{pH}$ of 6.5-7.9(Wang et al., 2002). The $\mathrm{pH}$ of Yongjiang river was within this range. Dissolved oxygen concentration ranged from 2.0 to $12.5 \mathrm{mg} / \mathrm{L}$ during the study period. The reported environmental standard for river water is $5 \mathrm{mg} / \mathrm{L}(\mathrm{GB}, 2002)$. DO of Yongjiang river was partially lower than the reported standard during the monitoring period; these results show that the water is contaminated by organic matter, the oxygen consumption is severe, dissolved oxygen can not be replenished in time, and the anaerobic bacteria in the water will multiply quickly (Wang et al., 2002). DO showed a negative correlation of TMC-LR with TMCs in Yongjiang river. However, some studies indicated that increases in oxygen saturation were correlated with algal biomass (Bi et al., 2017). Nonetheless, the algal abundance (or biomass) such as chlorophyll-a concentration or algal cell counts was not measured, and thus, DO has no direct effect on the concentration levels of toxins. The correlation analysis results indicated that increasing the TP concentration could increase the concentration levels of toxins, especially that of TMC-LR. The current observations were in agreement with those from a study conducted in the large eutrophic Lake Erie in the USA (Harke et al., 2016), which demonstrated positive 
370

371

372

373

374

375

376

377

378

379

380

381

382

383

384

385

386

387

388

389

correlations between TP and the abundance of toxic Microcystis and MCs. Consistent with the trend, Vézie et al. (2002) also found that higher P concentrations were beneficial to the growth of toxic Microcystis. Although TP was a dominant explanatory variable, the effect of TN on the concentration levels of toxins could not be ignored. The concentration of TMC-YR was negatively correlated with the TN/TP ratio. Previous studies also demonstrated that decreasing the TN/TP ratio concentration could promote the growth and toxin concentration of Microcystis (Yu et al., 2014; Lei et al., 2015). According to stepwise multiple linear regression (Table 3), TP was found to be the dominant factor affecting the contents of TMC-LR and TMCs, and pH and TN/TP ratio as the main factors affecting the content of TMC-RR and TMC-YR. These findings were in agreement with the results of correlation analysis.

The Monte Carlo simulation model determined the risk level and putative human exposure scenarios associated with the blooms in the Yongiiang river used for drinking. The whole process of security risk assessment was always accompanied by the uncertainty. The entire process of risk assessment was conducted in two steps: exposure assessment and hazard characterization. Although the extrapolation of the experimental results does not lead to certainty, it could be carried out from experimental animals to the general population and from the general population to specific populations (sensitive populations). The variations in human individuals involved parameters such as genetics, age, sex, environment (nutritional status) and other factors. On the other hand, missing data or limitations led to uncertainties, including NOVEL, time differences, and lack of exposure data. Recent studies have gradually established superior 
390

391

392

393

394

395

396

397

398

399

400

401

402

403

404

405

406

407

408

409

methods, such as benchmark dose (BMD) and chemical-specific adjustment factor (CSAF), to address and reduce the uncertainty in the risk assessment (Ibelings et al., 2015). The USEPA and Health Canada have gradually started utilizing the BMD and CSAF methods to develop the health guidance values (Zeller, Duran-Pacheco \& Guerard, 2017).

Several countries that regulate cyanotoxins in drinking water use a parametric value based on the WHO Guidelines for $1 \mu \mathrm{g} / \mathrm{L}$ MC-LR (WHO, 2017). With respect to the drinking source waters, most countries use guideline values based on cyanobacterial biomass (cell density, chlorophyll-a, biovolume) indirectly reflecting the potential hazardous MCs concentrations (Valerio et al., 2009; Menezes, Churro \& Dias, 2017). Our results indicated that the risk of carcinogenicity of MC-RR to children health under high exposure was greater than the maximum acceptable risk level recommended by USEPA $\left(1 \times 10^{-4}\right)$; the annual risk of carcinogenic exposure in adults with MC-RR was greater than the maximum acceptable risk level recommended by the ICRP $\left(5 \times 10^{-5}\right)$. The TMC-RR concentrations varied from 0.0224 to $0.3783 \mu \mathrm{g} / \mathrm{L}$ during the monitoring period. Therefore, the guideline value of TMC-RR in the Yongjiang river should be $<0.3783 \mu \mathrm{g} / \mathrm{L}$, so as not to pose a health risk to humans. Furthermore, we must take into account the increasing usage of the Yongjiang river, not only for the production of drinking water, but also for ludic activities, such as water sports, fishing, sailing and swimming. Thus, the relevant departments must attach great importance to the potential risks associated with the Yongjiang river in order to protect the health of their users.

\section{CONCLUSION}


410 This study analyzed the influencing factors and the health risk assessment of MCs by Monte

411 Carlo simulation in the Yongjiang river, China. The results showed that TP content may be

412 related to TMC-LR and TMCs concentration, while $\mathrm{pH}$ and TN/TP ratio may be related to TMC-

413 RR and TMC-YR concentration, respectively. The health risk assessment results showed that the

414 risk of MC-RR for human health hazards is higher than that of MC-LR and MC-YR, and

415 children are more vulnerable to MCs contamination than the adults. The risk of carcinogenicity

416 of MC-RR to children health under high exposure was greater than the maximum acceptable risk

417 level recommended by USEPA. The annual risk of carcinogenic exposure in adults with MC-RR

418 was greater than the maximum acceptable risk level recommended by the ICRP. The non-

419 carcinogenic hazard index for MCs was $<1$. Therefore, MCs in the water bodies should be

420 monitored with regarding to the carcinogenic risk to human health.

\section{ACKNOWLEDGEMENTS}

422 The authors appreciate the Affiliated Tumor Hospital of Guangxi Medical University for their

423 support in this study.

\section{REFERENCES}

425 Bi X, Dai W, Zhang S, Dong S, Zhang D. 2017. Effects of toxic Microcystis genotypes on 426 natural colony formation and mechanism involved. Water Sci Technol 76(4): 885-894.

427 Cao Q, Steinman AD, Yao L, Xie L. 2017. Toxicological and biochemical responses of the 428 earthworm Eisenia fetida to cyanobacteria toxins. Sci Rep 7(1): 15954.

429 Clausen JL, Georgian T, Gardner KH, Douglas TA. 2017. Applying Incremental Sampling 430 Methodology to Soils Containing Heterogeneously Distributed Metallic Residues to Improve 431 Risk Analysis. Bull Environ Contam Toxicol.

432 Cummins E, Butler F, Gormley R, Brunton N. 2009. A Monte Carlo risk assessment model for 433 acrylamide formation in French fries. Risk Anal 29(10): 1410-1426. 
434 Duy TN, Lam PK, Shaw GR, Connell DW. Toxicology and risk assessment of freshwater 435 cyanobacterial (blue-green algal) toxins in water. Rev Environ Contam Toxicol 163: 113-185.

436 Falconer, I. R. and T. H. Buckley. 1989. Tumour promotion by Microcystis sp., a blue-green alga 437 occurring in water supplies. Med J Aust 150(6): 351.

438 Fan Ch, E.J.Love, Zhai PY, Wang J, Na HK .2009. Risk assessment of liver cancer caused by

439

440

441

442

443 organic poisons in S river water. Mutant Society for Carcinogenicity 2009:7(in Chinese).

Funari, E. and E. Testai. 2008. Human health risk assessment related to cyanotoxins exposure. Crit Rev Toxicol 38(2): 97-125.

Guo Biao(GB) 3838-2002. Environmental quality standards for surface water(in Chinese) .

Harke MJ, Davis TW, Watson SB, Gobler CJ.2016. Nutrient-Controlled Niche Differentiation of Western Lake Erie Cyanobacterial Populations Revealed via Metatranscriptomic Surveys. Environ Sci Technol 50(2): 604-615.

Hitzfeld BC, Hoger SJ, Dietrich DR. 2000. Cyanobacterial toxins: removal during drinking water treatment, and human risk assessment. Environ Health Perspect 108 Suppl 1: 113-122.

Holland, A.; Kinnear, S. 2013. Interpreting the possible ecological role(s) of cyanotoxins: Compounds for competitive advantage and/or physiological aid? Mar. Drugs, 11(7), 2239-2258. International Agency for Research on Cancer(IARC). 2010. monographs on the evaluation of carcinogenic risks to humans. Ingested nitrate and nitrite, and cyanobacterial peptide toxins. IARC Monogr Eval Carcinog Risks Hum 94: v-vii, 1-412.

Ibelings BW, Backer LC, Kardinaal WE, Chorus I. 2015. Current approaches to cyanotoxin risk assessment and risk management around the globe. Harmful Algae 49: 63-74.

Jia Y, Wang L, Cao J, Li S, Yang Z. 2018. Trace elements in four freshwater fish from a mineimpacted river: spatial distribution, species-specific accumulation, and risk assessment. Environ Sci Pollut Res Int.

Keleti, G., Sykora, J.L., Libby, E.C. and Shapiro, M.A. 1979. Composition and biological properties of lipopolysaccharides isolated from Schizothrix calcicola (Ag.) Gomont (cyanobacteria). Appl. Environ. Microbiol.,38, 471-477.

Keleti, G. and J. L. Sykora. 1982. Production and properties of cyanobacterial endotoxins. Appl Environ Microbiol 43(1): 104-109.

Lee S, Jiang X, Manubolu M, Riedl K, Ludsin SA, Martin JF, Lee J. 2017. Fresh produce and their soils accumulate cyanotoxins from irrigation water: Implications for public health and food security. Food Res Int 102: 234-245.

Lei L, Li C, Peng L, Han BP. 2015. Competition between toxic and non-toxic Microcystis aeruginosa and its ecological implication. Ecotoxicology 24(7-8): 1411-1418.

Li, D., A. Z. Gu and M. He. 2014. Quantification and genetic diversity of total and microcystinproducing Microcystis during blooming season in Tai and Yang-cheng lakes, China. J Appl Microbiol 116(6): 1482-1494.

Li G, Zhao X, Wu S, Hua H, Wang Q, Zhang Z. 2017. Dietary exposure to aluminium in the popular Chinese fried bread youtiao. Food Addit Contam Part A Chem Anal Control Expo Risk Assess 34(6): 972-979.

Li KZ, Deng W, Li YX, Li JL, Zhang CY, Ren JJ, Wu HH .2016. Microcystin content of 
475 different water sources in a region of Guangxi showing high incidence of liver cancer. Chin $\mathrm{J}$ of 476 Oncol Prev and Treat. 2016,8(06):387-390(in Chinese).

477 Lippy, E.C. and Erb, J. 1976 Gastrointestinal illness at Sewickley, PA. J. Am. Water Works 478 Assoc., 68, 606-610.

479 Lipton J, Shaw WD, Holmes J, Patterson A. 1995. Short communication: selecting input 480 distributions for use in Monte Carlo simulations. Regul Toxicol Pharmacol 21(1): 192-198.

481 LV BJ, Pan J, Wu SSH, Wei CHY, Li CHM, WU HY. 2005. Investigation on the content of 482 microcystin in drinking source water and factory water in Guangxi. Chin J Nat Med 483 2005(04):313-314(in Chinese).

484 Mantzouki E. 2018. Temperature Effects Explain Continental Scale Distribution of 485 Cyanobacterial Toxins. Toxins (Basel) 13;10(4).

486 Menezes, C., C. Churro and E. Dias. 2017. Risk Levels of Toxic Cyanobacteria in Portuguese 487 Recreational Freshwaters. Toxins (Basel) 9(10).

488 Moolenaar RJ. 1996. A perspective on carcinogen risk assessment. Toxicology Forum, 489 Washington DC, February 19, 1996. Regul Toxicol Pharmacol 23(3): 241-243.

490 NHMRC, NRMMC. 2011. Australian Drinking Water Guidelines Paper 6 National Water 491 Quality Management Strategy. National Health and Medical Research Council, National 492 Resource Management Ministerial Council, Commonwealth of Australia, Canberra.

493 Paladino, O., A. Moranda and M. Seyedsalehi. 2017. A Method for Identifying Pollution Sources 494 of Heavy Metals and PAH for a Risk-Based Management of a Mediterranean Harbour. 495 Scientifica (Cairo) 2017: 4690715.

496 Pham TL, Utsumi M. 2018. An overview of the accumulation of microcystins in aquatic 497 ecosystems. J Environ Manage 213:520-529.

498 Pouria S, de Andrade A, Barbosa J, Cavalcanti RL, Barreto VT, Ward CJ, Preiser W, Poon GK, 499 Neild GH, Codd GA. 1998. Fatal microcystin intoxication in haemodialysis unit in Caruaru, 500 Brazil. Lancet 352(9121): 21-26.

501 Jia Y, Wang L, Cao J, Li S, Yang Z. 2017. Monte Carlo simulations of skin exposure to 502 electromagnetic field from $10 \mathrm{GHz}$ to $1 \mathrm{THz}$. Phys Med Biol 62(17): 6993-7010.

503 Sasi, H., A. Yozukmaz and M. Yabanli. 2017. Heavy metal contamination in the muscle of 504 Aegean chub (Squalius Fellowesii) and potential risk assessment. Environ Sci Pollut Res Int.

505 Ueno Y, Nagata S, Tsutsumi T, Hasegawa A, Watanabe MF, Park HD, Chen GC, Chen G, Yu 506 SZ. 1996. Detection of microcystins, a blue-green algal hepatotoxin, in drinking water sampled 507 in Haimen and Fusui, endemic areas of primary liver cancer in China, by highly sensitive 508 immunoassay. Carcinogenesis 17(6): 1317-1321.

509 Valerio E, Chambel L, Paulino S, Faria N, Pereira P, Tenreiro R. 2009. Molecular identification, 510 typing and traceability of cyanobacteria from freshwater reservoirs. Microbiology 155(Pt 2): $511 \quad 642-656$.

512 Vezie C, Rapala J, Vaitomaa J, Seitsonen J, Sivonen K. 2002. Effect of nitrogen and phosphorus 513 on growth of toxic and nontoxic Microcystis strains and on intracellular microcystin 514 concentrations. Microb Ecol 43(4): 443-454.

515 Wang Q, Niu Y, Xie P, Chen J, Ma Z, Tao M, Qi M, Wu L, Guo L. 2010. Factors affecting 
516 temporal and spatial variations of microcystins in Gonghu Bay of Lake Taihu, with potential risk 517 of microcystin contamination to human health. ScientificWorldJournal 10: 1795-1809.

518 Wang X, Parkpian P, Fujimoto N, Ruchirawat KM, DeLaune RD, Jugsujinda A. 2002. 519 Environmental conditions associating microcystins production to Microcystis aeruginosa in a 520 reservoir of Thailand. J Environ Sci Health A Tox Hazard Subst Environ Eng 37(7):1181-207.

521 Watanabe, M.F., Harada, K.I., Carmichael, W.W., Fujiki. 1996. Production of Microcystins. In 522 Toxic Microcystis; CRC Press: Boca Raton, Fla. 1996; 35-36.

523 World Health Organization(WHO). 2017. Guidelines for drinking-water quality: fourth edition 524 incorporating the first addendum. Geneva. Licence: CC BY-NC-SA 3.0 IGO

525 Wolf, H. U. and C. Frank. 2002. Toxicity assessment of cyanobacterial toxin mixtures. Environ 526 Toxicol 17(4): 395-399.

527 Wunderlin DA, Diaz MP, Ame' MV, Pesce SF, Hued AC, Bistoni MA. 2001. Pattern 528 recognition techniques for the evaluation of spatial and temporal variations in water quality. A 529 case study: Suqu'1a River Basin (Co'rdoba -Argentina). Water Res 35:2881-2894.

530 Xu Y, Wang G, Yang W, Li R. 2010. Dynamics of the water bloom-forming Microcystis and its 531 relationship with physicochemical factors in Lake Xuanwu (China). Environ Sci Pollut Res Int 532 17(9): 1581-1590.

533 Yang H, Xie P, Xu J, Zheng L, Deng D, Zhou Q, Wu S. 2006. Seasonal variation of microcystin 534 concentration in Lake Chaohu, a shallow subtropical lake in the People's Republic of China. Bull 535 Environ Contam Toxicol 77(3): 367-374.

536 Yeh FS, Yu MC, Mo CC, Luo S, Tong MJ, Henderson BE. 1989. Hepatitis B virus, aflatoxins, 537 and hepatocellular carcinoma in southern Guangxi, China. Cancer Res 49(9): 2506-2509.

538 Younes, M. 1999. Specific issues in health risk assessment of endocrine disrupting chemicals 539 and international activities. Chemosphere 39(8): 1253-1257.

540 Yu L, Kong F, Zhang M, Yang Z, Shi X, Du M. 2014. The dynamics of microcystis genotypes 541 and microcystin production and associations with environmental factors during blooms in Lake 542 Chaohu, China. Toxins (Basel) 6(12): 3238-3257.

543 Yu SZ, Chen W, Li J .1995. The prospective research of risk factors of primary liver cancer in 544 Nanhui County, Shanghai. Zhonghua Liu Xing Bing Xue Za Zhi 16(1):22-4(in Chinese).

545 Zegura, B. 2016. An Overview of the Mechanisms of Microcystin-LR Genotoxicity and 546 Potential Carcinogenicity. Mini Rev Med Chem 16(13): 1042-1062.

547 Zeller, A., G. Duran-Pacheco and M. Guerard. 2017. An appraisal of critical effect sizes for the 548 benchmark dose approach to assess dose-response relationships in genetic toxicology. Arch 549 Toxicol 91(12): 3799-3807.

550 Zobitz JM, Desai AR, Moore DJ, Chadwick MA. 2011. A primer for data assimilation with 551 ecological models using Markov Chain Monte Carlo (MCMC). Oecologia 167(3): 599-611. 


\section{Table $\mathbf{1}$ (on next page)}

Results of analysis of MCs in water samples

The total concentrations of MCS (TMCS) in water is the sum of the concentrations of extracellular MCS (EMCS) and intracellular MCS (IMCS) dissolved in the water; standard deviation means $S D$. 


\begin{tabular}{|c|c|c|c|c|c|}
\hline \multirow[t]{2}{*}{$\begin{array}{l}\text { Toxin } \\
\text { types }\end{array}$} & \multirow{2}{*}{$\begin{array}{l}\text { Number } \\
\text { of } \\
\text { samples }\end{array}$} & EMCs & IMCs & concent & ation $(\mu \mathrm{g} / \mathrm{L})$ \\
\hline & & Detection Rate(\%) & Detection Rate $(\%)$ & Range & Mean $\pm S D$ \\
\hline MC-RR & 90 & 74.44 & 77.78 & $0.0224-0.3783$ & $0.0727 \pm 0.0599$ \\
\hline MC-YR & 90 & 64.44 & 56.67 & $0.0329-0.1433$ & $0.0424 \pm 0.0376$ \\
\hline MC-LR & 90 & 77.78 & 76.67 & $0.0341-0.2663$ & $0.0763 \pm 0.0637$ \\
\hline
\end{tabular}




\section{Table 2 (on next page)}

Correlation coefficients between MCs and the influencing factors

*Correlation is significant at the 0.05 level (2-tailed).**Correlation is significant at the 0.01 level (2-tailed). 


\begin{tabular}{|c|c|c|c|c|}
\hline \multirow{2}{*}{ Environmental Factors } & \multicolumn{4}{|c|}{ Correlation Coefficient } \\
\hline & TMC-RR & TMC-YR & TMC-LR & TMCs \\
\hline $\begin{array}{c}\text { Water } \\
\text { Temperature }\end{array}$ & $0.436 * *$ & 0.085 & $0.480 * *$ & $0.614^{* *}$ \\
\hline $\mathrm{PH}$ & $-0.729 * *$ & -0.029 & -0.164 & $-0.566^{* *}$ \\
\hline DO & -0.063 & -0.076 & $-0.768 * *$ & $-0.570 * *$ \\
\hline $\mathrm{TN}$ & $0.286 * *$ & -0.179 & -0.079 & 0.055 \\
\hline $\mathrm{TP}$ & 0.043 & 0.073 & $0.851^{* *}$ & $0.610^{* *}$ \\
\hline $\mathrm{PO}_{4}{ }^{3--} \mathrm{P}$ & -0.047 & -0.071 & $0.399 * *$ & 0.204 \\
\hline TN:TP ratio & 0.040 & $-0.229 *$ & $-0.434 * *$ & $-0.347^{* *}$ \\
\hline
\end{tabular}




\section{Table 3(on next page)}

Results of stepwise multiple linear regression

The fitting result of TMC-YR after lg10 conversion; D-W statistic (Durbin-Watson statistic); Variance Inflation Factor(VIF). 


\begin{tabular}{|c|c|c|c|c|c|c|c|c|c|}
\hline \multirow{2}{*}{ MCs } & \multirow{2}{*}{ Fitting equation } & \multirow{2}{*}{$\begin{array}{l}\text { Correlation } \\
\text { coefficient R } \\
\end{array}$} & \multirow{2}{*}{ Adjusted $\mathrm{R}^{2}$} & \multirow{2}{*}{ Tolerance } & \multirow{2}{*}{ VIF } & \multicolumn{2}{|c|}{ Model fitting } & \multirow{2}{*}{$\begin{array}{l}\text { Partial regression } \\
\text { coefficient test }\end{array}$} & \multirow{2}{*}{$\begin{array}{c}\mathrm{D}-\mathrm{W} \\
\text { statistic }\end{array}$} \\
\hline & & & & & & $\mathrm{F}$ & $P$ & & \\
\hline \multirow[b]{3}{*}{ TMCs } & $y=116.848+46.449 \times 3$ & 0.581 & 0.337 & 1 & 1 & 44.792 & $<0.001$ & $\chi^{3} \quad(\mathrm{t}=6.693, \mathrm{P}<0.001)$ & \multirow[b]{3}{*}{1.979} \\
\hline & $y=805.526+42.979 \chi^{3}-92.886 \chi^{2}$ & 0.716 & 0.513 & 0.989 & 1.001 & 45.87 & $<0.001$ & $\begin{array}{l}\chi^{3} \quad(t=7.148, P<0.001) \\
\chi^{2}(t=-5.608, P<0.001)\end{array}$ & \\
\hline & $y=538.069+35.557 \chi 3-75.968 \chi 2+6.452 \chi 1$ & 0.741 & 0.549 & 0.693 & 1.443 & 34.938 & $<0.001$ & $\begin{array}{l}\chi 3 \quad(t=5.495, \mathrm{P}<0.001) \\
\chi 2 \quad(\mathrm{t}=-4.396, \mathrm{P}<0.001) \\
\chi 1 \quad(\mathrm{t}=2.622, \mathrm{P}=0.01)\end{array}$ & \\
\hline \multirow{3}{*}{ TMC-RR } & $y=799.874-99.263 \times 2$ & 0.718 & 0.515 & 1 & 1 & 93.396 & $<0.001$ & $\chi^{2}(\mathrm{t}=-9.664, \mathrm{P}<0.001)$ & \multirow{3}{*}{1.828} \\
\hline & $\mathrm{y}=825.53-101.047 \chi 2-35.61 \chi 4$ & 0.738 & 0.544 & 0.994 & 1.006 & 51.98 & $<0.001$ & $\begin{array}{l}\chi^{2}(t=-10.066, P<0.001) \\
\chi^{4}(t=-2.375, P=0.02)\end{array}$ & \\
\hline & $\mathrm{y}=676.095-91.169 \chi^{2}-39.668 \chi 4+3.42 \chi 1$ & 0.759 & 0.576 & 0.846 & 1.181 & 38.908 & $<0.001$ & $\begin{array}{l}\chi^{2}(\mathrm{t}=-8.682, \mathrm{P}<0.001) \\
\chi^{4}(\mathrm{t}=-2.709, \mathrm{P}<0.001) \\
\chi 1 \quad(\mathrm{t}=2.522, \mathrm{P}=0.014)\end{array}$ & \\
\hline TMC-YR & $\mathrm{y}=1.54-0.013 \chi^{7}$ & 0.268 & 0.072 & 1 & 1 & 6.83 & 0.011 & $\chi^{3}(\mathrm{t}=-2.613, \mathrm{P}=0.011)$ & 2.299 \\
\hline \multirow[b]{2}{*}{ TMC-LR } & $y=11.216+41.829 \chi^{3}$ & 0.806 & 0.650 & 1 & 1 & 163.585 & $<0.001$ & $\left.\chi^{3} （ \mathrm{t}=12.79, \mathrm{P}<0.001\right)$ & \multirow[b]{2}{*}{1.461} \\
\hline & $\mathrm{y}=63.349+32.481 \chi^{3}-6.653 \chi 6$ & 0.848 & 0.718 & 0.678 & 1.476 & 111.004 & $<0.001$ & $\begin{array}{l}\chi^{3}(\mathrm{t}=9.06, \mathrm{P}<0.001) \\
\chi 6 \quad(\mathrm{t}=-4.592 \mathrm{P}<0.001)\end{array}$ & \\
\hline
\end{tabular}




\section{Table 4(on next page)}

Fitting distribution and related parameters of MCs in source water $(\mu \mathrm{g} / \mathrm{L})$ 


\begin{tabular}{|c|c|c|c|c|c|c|c|c|c|}
\hline \multirow{2}{*}{ MCs } & \multirow{2}{*}{$\begin{array}{l}\text { Fitting of } \\
\text { Distribution }\end{array}$} & \multicolumn{2}{|c|}{$\begin{array}{l}\text { Distributed } \\
\text { parameters }\end{array}$} & \multicolumn{3}{|c|}{ Fit test sort } & \multirow{2}{*}{$\begin{array}{c}50 \% \\
\text { Confidence } \\
\text { value }\end{array}$} & \multirow{2}{*}{$\begin{array}{c}90 \% \\
\text { Confidence } \\
\text { value }\end{array}$} & \multirow{2}{*}{$\begin{array}{c}95 \% \\
\text { Confidence } \\
\text { value }\end{array}$} \\
\hline & & Mean & Std Dev & $\mathrm{K}-\mathrm{S}$ & A-D & Chi-Sq & & & \\
\hline \multirow{3}{*}{ MC-RR } & Gamma & 0.073 & 0.061 & 1 & 1 & 1 & 0.056 & 0.154 & 0.194 \\
\hline & Invgauss & 0.073 & 0.066 & 5 & 2 & 2 & 0.053 & 0.154 & 0.202 \\
\hline & Lognorm & 0.047 & 0.071 & 4 & 2 & 1 & 0.026 & 0.103 & 0.154 \\
\hline \multirow[t]{2}{*}{ MC-YR } & Expon & 0.042 & 0.039 & 2 & 1 & 4 & 0.030 & 0.093 & 0.120 \\
\hline & Loglogistic & 0.081 & - & 1 & 4 & 6 & 0.026 & 0.124 & 0.216 \\
\hline \multirow{2}{*}{ MC-LR } & Gamma & 0.076 & 0.070 & 1 & 1 & 2 & 0.055 & 0.168 & 0.216 \\
\hline & Expon & 0.075 & 0.073 & 2 & 2 & 1 & 0.053 & 0.170 & 0.221 \\
\hline
\end{tabular}




\section{Table 5 (on next page)}

Estimated value of the quantile for overall sample in different theoretical distributions 


\begin{tabular}{|c|c|c|c|c|c|}
\hline Projects & Pollutant & Real value $(\mu \mathrm{g} / \mathrm{L})$ & Types & $\begin{array}{l}\text { Predicted value } \\
\qquad(\mu \mathrm{g} / \mathrm{L})\end{array}$ & $\begin{array}{l}\text { Relative difference of real } \\
\text { value }(\%)\end{array}$ \\
\hline \multirow{9}{*}{ P50 } & \multirow{3}{*}{ MC-RR } & \multirow{3}{*}{0.058} & Gamma & 0.056 & 3.01 \\
\hline & & & & & \\
\hline & & & Invgauss & 0.053 & 7.81 \\
\hline & \multirow{3}{*}{ MC-YR } & \multirow{3}{*}{0.024} & Lognorm & 0.026 & 8.82 \\
\hline & & & Expon & 0.030 & 25.17 \\
\hline & & & Loglogistc & 0.026 & 10.03 \\
\hline & \multirow{3}{*}{ MC-LR } & \multirow{3}{*}{0.057} & Gamma & 0.055 & 2.02 \\
\hline & & & & & \\
\hline & & & Expon & 0.053 & 6.10 \\
\hline \multirow{9}{*}{ P75 } & \multirow{3}{*}{ MC-RR } & \multirow{3}{*}{0.011} & Gamma & 0.099 & 13.00 \\
\hline & & & & & \\
\hline & & & Invgauss & 0.095 & 16.91 \\
\hline & \multirow{3}{*}{ MC-YR } & \multirow{3}{*}{0.062} & Lognorm & 0.053 & 13.88 \\
\hline & & & Expon & 0.057 & 8.17 \\
\hline & & & Loglogistc & 0.056 & 9.41 \\
\hline & \multirow{3}{*}{ MC-LR } & \multirow{3}{*}{0.112} & Gamma & 0.104 & 6.79 \\
\hline & & & & & \\
\hline & & & Expon & 0.104 & 7.46 \\
\hline \multirow{6}{*}{ P90 } & \multirow{3}{*}{ MC-RR } & \multirow{3}{*}{0.136} & Gamma & 0.154 & 12.93 \\
\hline & & & & & \\
\hline & & & Invgauss & 0.154 & 13.09 \\
\hline & \multirow{3}{*}{ MC-YR } & \multirow{3}{*}{0.108} & Lognorm & 0.103 & 4.31 \\
\hline & & & & & \\
\hline & & & Expon & 0.093 & 14.10 \\
\hline
\end{tabular}




\begin{tabular}{|c|c|c|c|c|c|}
\hline & & & Loglogistc & 0.124 & 15.12 \\
\hline & & & Gamma & 0.168 & 1.09 \\
\hline & MC-LR & 0.166 & & & \\
\hline & & & Expon & 0.170 & 2.46 \\
\hline \multirow{9}{*}{ P95 } & & & Gamma & 0.194 & 16.26 \\
\hline & MC-RR & 0.167 & & & \\
\hline & & & Invgauss & 0.202 & 21.06 \\
\hline & & & Lognorm & 0.154 & 29.08 \\
\hline & MC-YR & 0.119 & Expon & 0.120 & 0.58 \\
\hline & & & Loglogistc & 0.216 & 80.78 \\
\hline & & & Gamma & 0.216 & 0.26 \\
\hline & MC-LR & 0.215 & & & \\
\hline & & & Expon & 0.221 & 2.56 \\
\hline \multirow{9}{*}{ P99 } & & & Gamma & 0.285 & 24.71 \\
\hline & MC-RR & 0.378 & & & \\
\hline & & & Invgauss & 0.321 & 15.02 \\
\hline & & & Lognorm & 0.325 & 127.11 \\
\hline & MC-YR & 0.143 & Expon & 0.183 & 27.56 \\
\hline & & & Loglogistc & 0.735 & 412.77 \\
\hline & & & Gamma & 0.326 & 22.62 \\
\hline & MC-LR & 0.266 & & & \\
\hline & & & Expon & 0.338 & 27.03 \\
\hline
\end{tabular}




\section{Table 6(on next page)}

Daily exposure to MCs intake through drinking water $(\mu \mathrm{g} / \mathrm{kg} / \mathrm{d})$ 


\begin{tabular}{|c|c|c|c|c|c|c|}
\hline \multirow{2}{*}{ Projects } & \multicolumn{2}{|c|}{ MC-RR } & \multicolumn{2}{|c|}{ MC-YR } & \multicolumn{2}{|c|}{ MC-LR } \\
\hline & Adult & Child & Adult & Child & Adult & Child \\
\hline Mean & 0.002 & 0.005 & 0.001 & 0.003 & 0.002 & 0.005 \\
\hline P50 & 0.002 & 0.004 & 0.001 & 0.001 & 0.002 & 0.004 \\
\hline P85 & 0.004 & 0.008 & 0.003 & 0.006 & 0.004 & 0.009 \\
\hline P90 & 0.004 & 0.009 & 0.003 & 0.007 & 0.005 & 0.010 \\
\hline P95 & 0.005 & 0.010 & 0.003 & 0.007 & 0.006 & 0.013 \\
\hline
\end{tabular}
1 
Table 7 (on next page)

Carcinogenic exposure of MCs from source water 


\begin{tabular}{|c|c|c|c|c|c|c|}
\hline \multirow{2}{*}{ Projects } & \multicolumn{2}{|c|}{ MC-RR } & \multicolumn{2}{|c|}{ MC-YR } & \multicolumn{2}{|c|}{ MC-LR } \\
\hline & Adult & Child & Adult & Child & Adult & Child \\
\hline Mean & $1.27 \times 10^{-5}$ & $1.37 \times 10^{-5}$ & $3.34 \times 10^{-6}$ & $5.76 \times 10^{-6}$ & $5.20 \times 10^{-6}$ & $8.10 \times 10^{-6}$ \\
\hline P50 & $1.40 \times 10^{-5}$ & $1.43 \times 10^{-5}$ & $2.21 \times 10^{-6}$ & $4.40 \times 10^{-6}$ & $4.69 \times 10^{-6}$ & $8.30 \times 10^{-6}$ \\
\hline P85 & $5.43 \times 10^{-5}$ & $1.13 \times 10^{-4}$ & $6.93 \times 10^{-6}$ & $1.09 \times 10^{-5}$ & $9.18 \times 10^{-6}$ & $1.28 \times 10^{-5}$ \\
\hline P90 & $5.47 \times 10^{-5}$ & $1.45 \times 10^{-4}$ & $7.60 \times 10^{-6}$ & $1.16 \times 10^{-5}$ & $9.85 \times 10^{-6}$ & $1.32 \times 10^{-5}$ \\
\hline P95 & $8.63 \times 10^{-5}$ & $1.83 \times 10^{-4}$ & $8.11 \times 10^{-6}$ & $1.20 \times 10^{-5}$ & $1.11 \times 10^{-5}$ & $1.38 \times 10^{-5}$ \\
\hline
\end{tabular}

1 


\section{Table 8 (on next page)}

Maximal acceptable level and negligible level recommended by different institutions 


\begin{tabular}{|c|c|c|c|}
\hline Institutions & $\begin{array}{l}\text { Maximum } \\
\text { risk level }\end{array}$ & $\begin{array}{l}\text { Ignore the } \\
\text { level of } \\
\text { risk }\end{array}$ & Remarks \\
\hline USEPA & $1 \times 10^{-4}$ & -- & Radiation \\
\hline ICRP & $5 \times 10^{-5}$ & -- & Radiation \\
\hline Royal Association of England & $1 \times 10^{-6}$ & $1 \times 10^{-7}$ & -- \\
\hline Holland Environmental Protection Agency & $1 \times 10^{-6}$ & $1 \times 10^{-8}$ & $\begin{array}{l}\text { Chemical } \\
\text { contaminants }\end{array}$ \\
\hline Swedish Environmental Protection Agency & $1 \times 10^{-6}$ & -- & $\begin{array}{l}\text { Chemical } \\
\text { contaminants }\end{array}$ \\
\hline
\end{tabular}


Table 9 (on next page)

Non-carcinogenic exposure risk of MCs using source water 


\begin{tabular}{|c|c|c|c|c|c|c|}
\hline \multirow{2}{*}{ Projects } & \multicolumn{2}{|c|}{ MC-RR } & \multicolumn{2}{|c|}{ MC-YR } & \multicolumn{2}{|c|}{ MC-LR } \\
\hline & Adult & Child & Adult & Child & Adult & Child \\
\hline Mean & 0.005190 & 0.011352 & 0.030260 & 0.066190 & 0.054490 & 0.119200 \\
\hline P50 & 0.004123 & 0.009019 & 0.017090 & 0.037380 & 0.040400 & 0.088380 \\
\hline P85 & 0.009157 & 0.020031 & 0.067480 & 0.147610 & 0.104530 & 0.228660 \\
\hline P90 & 0.009722 & 0.021267 & 0.077190 & 0.168840 & 0.118790 & 0.259860 \\
\hline P95 & 0.011903 & 0.026038 & 0.085150 & 0.186270 & 0.153860 & 0.336580 \\
\hline
\end{tabular}

1 
Figure 1

Sampling sites in the Yongjiang River

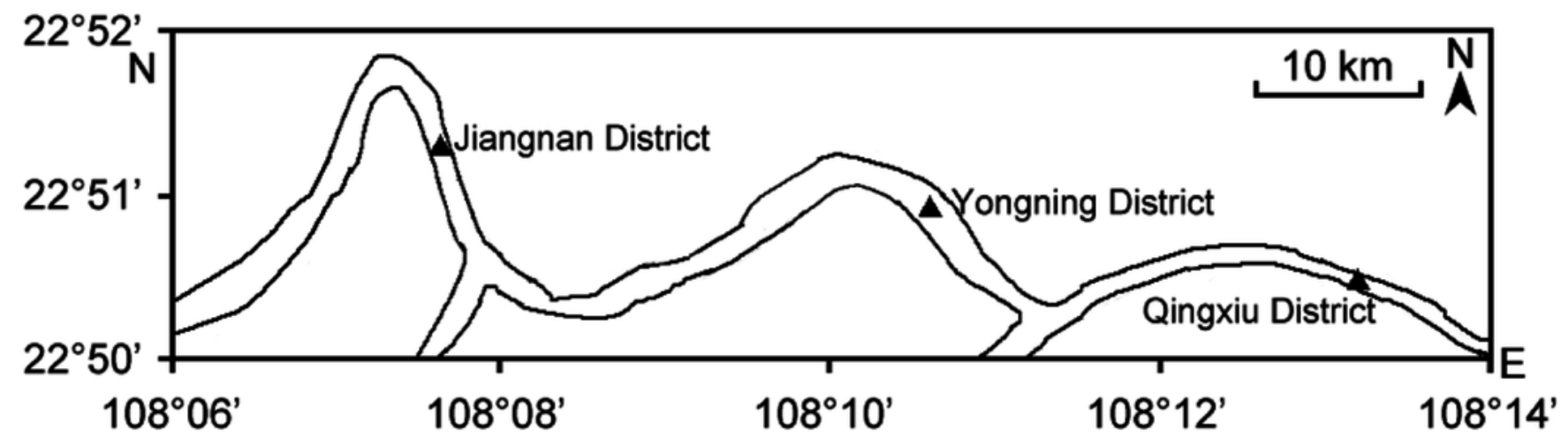


Figure 2

\section{HPLC chromatogram of MCS}

(A) HPLC chromatogram of MCs standards, the order of the peaks and time of each standard substance were as follows: MC-RR (7.599 min), MC-YR (14.225 min), and MC-LR (17.601 min). (B) HPLC chromatogram of MCs water samples, the same time represents the same substance, like $A$.
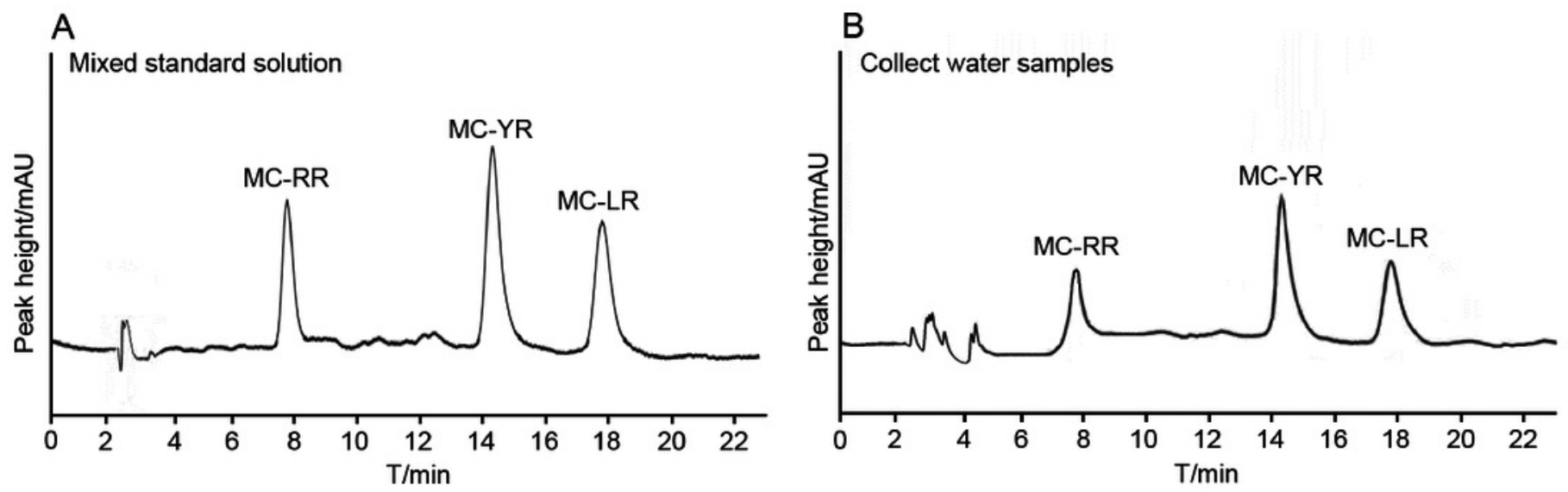
Figure 3

Concentration of MCs in source water in various seasons

TMCs is the sum of the total concentration (intracellular and extracellular) of each individual microcystin detected. This means, that TMCs=TMC-LR+TMC-RR+TMC-YR.

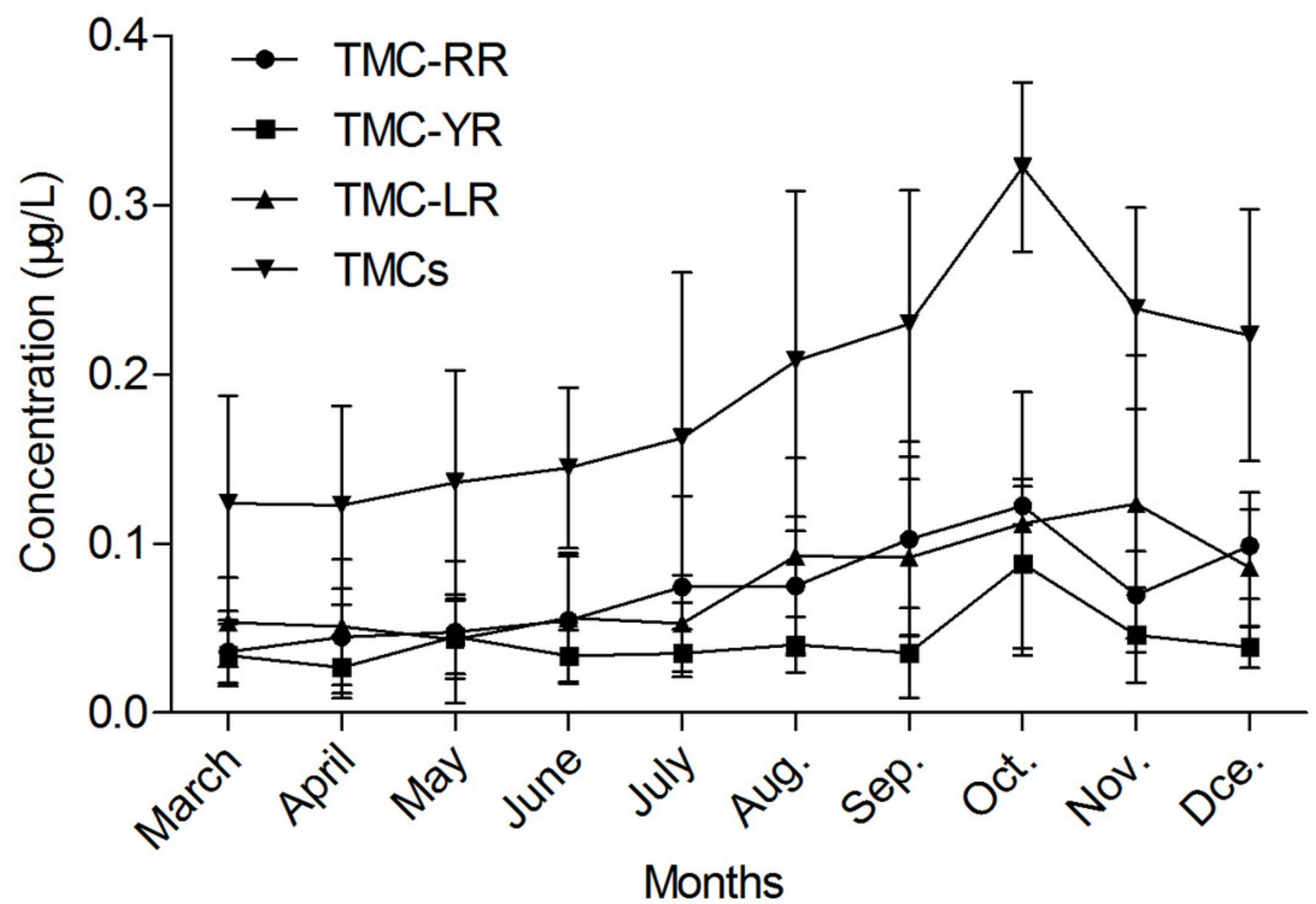




\section{Figure 4}

Probability distribution graph after fitting of MC-RR in source water $(\mu \mathrm{g} / \mathrm{L})$

The data comparison revealed that the optimal fitting distribution of the most suitable concentration of MC-RR in source water was Gamma $(\mu 0.073, \sigma 0.061)$ (first number $\mu$ as the position parameter and the second number $\mathrm{s}$ as the scale parameter). The abscissa in Figure 4 represents the concentrations of MC-RR; the concentrations are partitioned, the length of each interval is the group distance, the rectangular area is the frequency of the group, and the ratio of the total sample utilized, and the vertical axis is the frequency divided by the group distance obtained. The fitting results can be visually observed from the coincidence of the blue rectangular shape (93.9\%) and the area under the red curve (91.7\%).

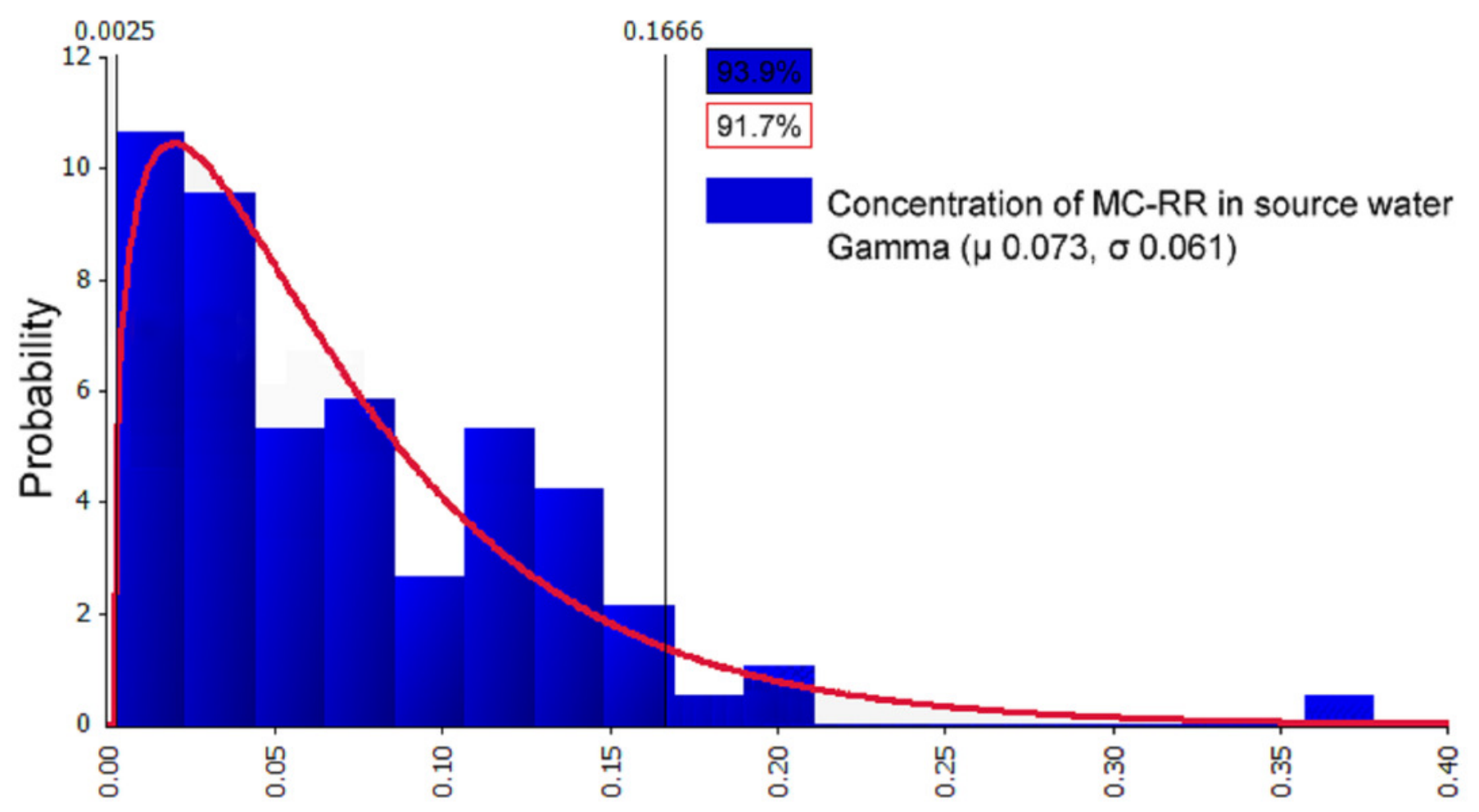




\section{Figure 5}

Probability distribution graph after fitting of MC-LR in source water $(\mu \mathrm{g} / \mathrm{L})$

The data comparison showed that the best-fitted distribution of MC-YR concentration was Lognorm ( $\mu$ 0.047, $\sigma 0.071)$. The abscissa in Figure 5 represents the concentrations of MC-YR; the concentrations are partitioned, the length of each interval is the group distance, the rectangular area is the frequency of the group, and the ratio of the total sample utilized, and the vertical axis is the frequency divided by the group distance obtained. The fitting results can be visually observed from the coincidence of the blue rectangular shape $(90.0 \%)$ and the area under the red curve $(88.9 \%)$.

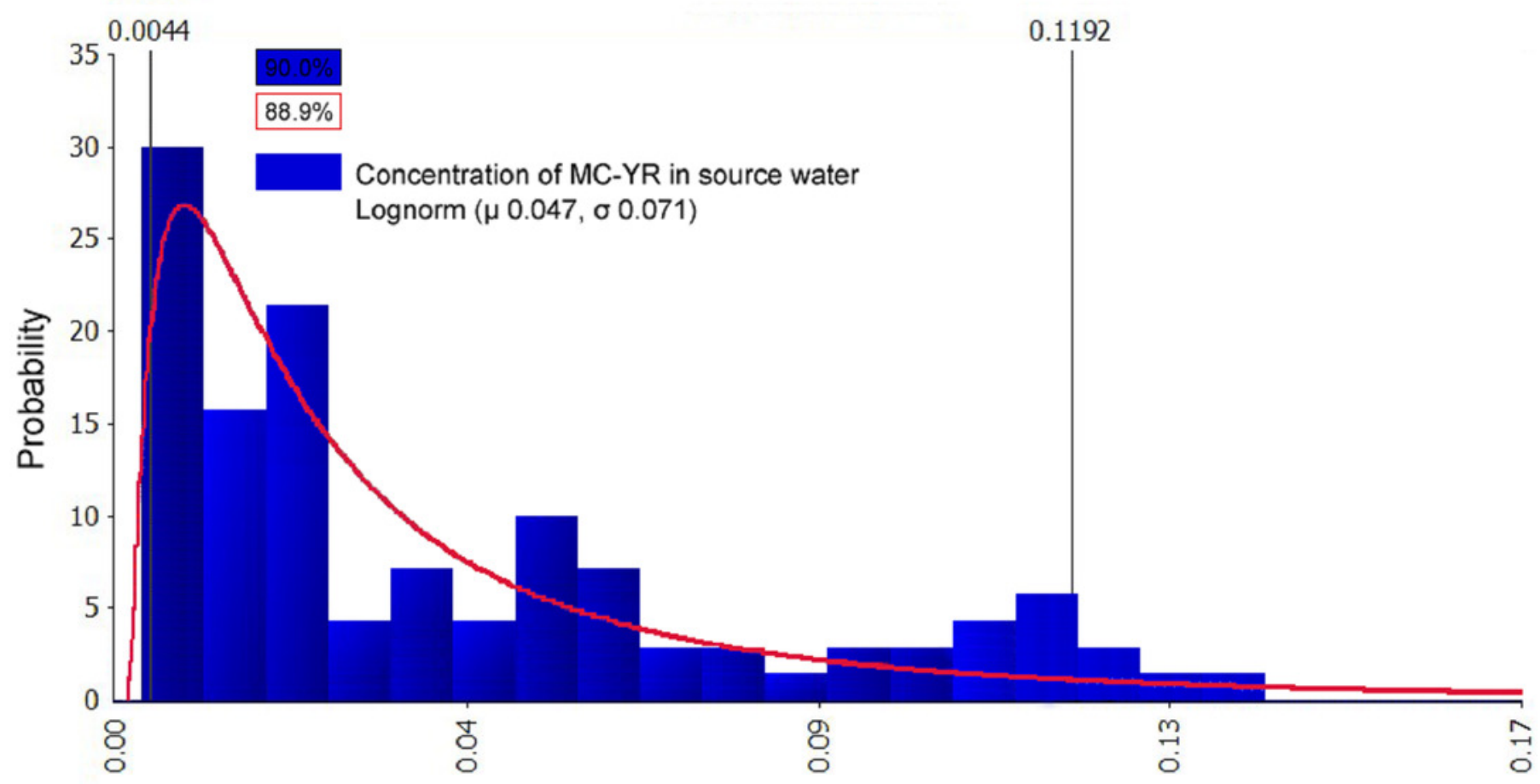




\section{Figure 6}

Probability distribution graph after fitting of MC-LR in source water $(\mu \mathrm{g} / \mathrm{L})$.

The data comparison showed that the best-fitted distribution of MC-LR concentration was Gamma $(\mu 0.076, \sigma 0.070)$. The abscissa in Figure 6 represents the concentrations of MC-LR; the concentrations are partitioned, the length of each interval is the group distance, the rectangular area is the frequency of the group, and the ratio of the total sample utilized, and the vertical axis is the frequency divided by the group distance obtained. The fitting results can be visually observed from the coincidence of the blue rectangular shape (90.0\%) and the area under the red curve (88.0\%).

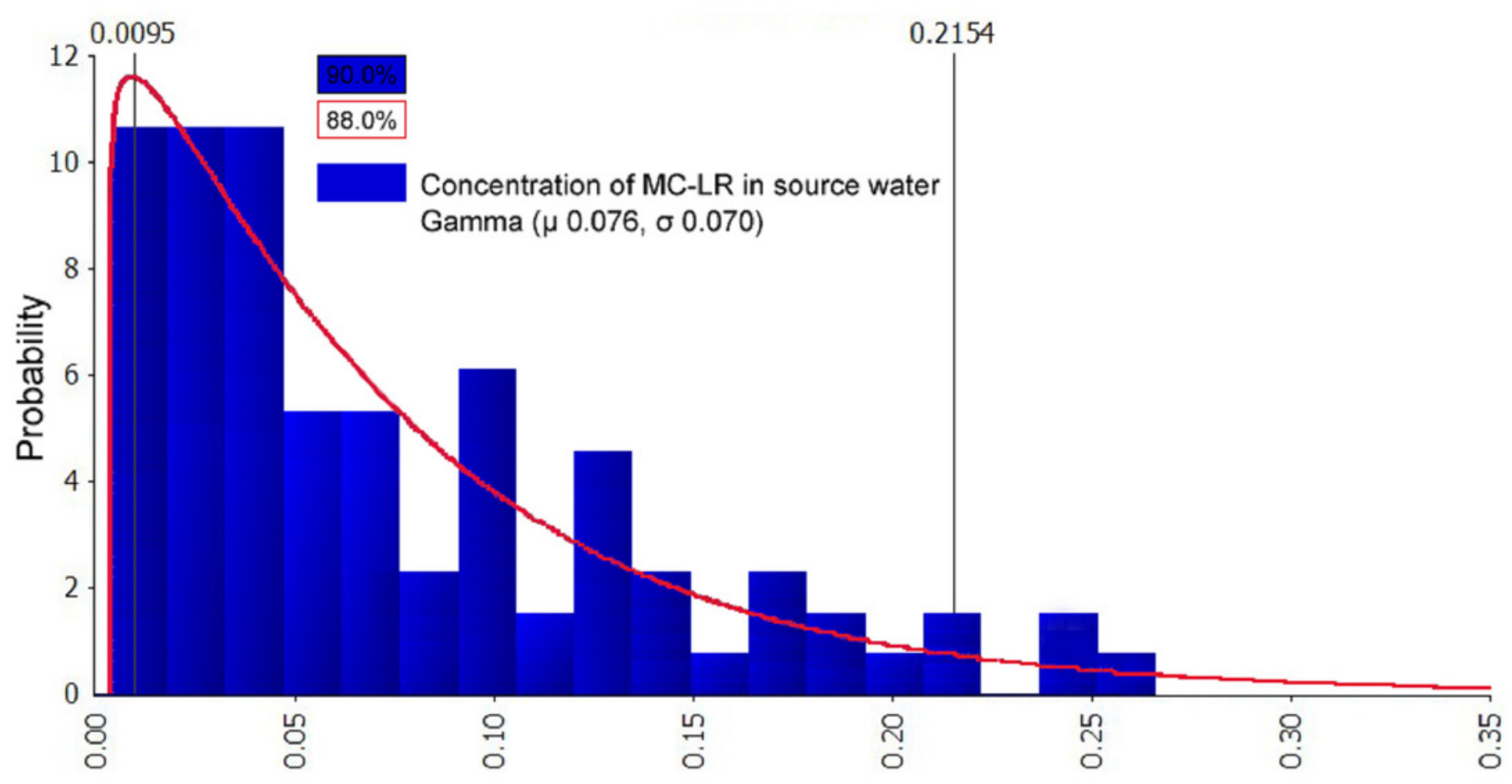

